\title{
Gender-Related Differences in Sensitivity to Diazinon in Gonads of Adult Rats and the Protective Effect of Vitamin E
}

\author{
Zinat Sargazi $^{1}$, Mohammad Reza Nikravesh $^{1}$, Mehdi Jalali ${ }^{1}$, Hamidreza Sadeghnia ${ }^{2}$, Fatemeh Rahimi Anbarkeh ${ }^{1}$, \\ Leila Mohammadzadeh ${ }^{3}$
}

\begin{abstract}
Objectives: Diazinon (DZN) is an organophosphate pesticide which is known to induce oxidative stress in the target tissues such as the reproductive system. The aim of present study was to compare and evaluate the effects of DZN on Malondialdehyde (MDA) and Glutathione (GSH) levels in testis and ovary of rats and to assess the protective role of vitamin E.

Materials and Methods: This study was conducted on 60 adult Wistar rats including 30 male and 30 female rats. Each of male and female groups included 30 rats and were divided into 5 groups: control (without any intervention), sham group (received only pure olive oil daily), treatment group 1 (received DZN+olive oil daily, $60 \mathrm{mg} / \mathrm{kg}$ ), treatment group 2 (received DZN, $60 \mathrm{mg} / \mathrm{kg}+$ vitamin E, $200 \mathrm{mg} / \mathrm{kg}$ daily) and treatment group 3 (received vitamin E daily, $200 \mathrm{mg} / \mathrm{kg}$ ). MDA and GSH levels were determined in gonads. Results: In both genders, due to administration of DZN, we found significant reduction in GSH content and increase in MDA level. The use of vitamin E plus DZN increased GSH content while decreased MDA level of ovary and testis compared with DZN treated rats. Gonad of female rats compared with male rats showed more increase in MDA level and further decline in GSH content in treatment groups 1 and 2 .

Conclusion: Oxidative stress contributes to DZN-induced sexual organ toxicity. Our results concluded that vitamin E may have a protective role in this toxicity. Female rats are likely more vulnerable to oxidative stress and its damages.

Keywords: Diazinon, Gonads, Oxidative Stress, Vitamin E
\end{abstract}

\section{Introduction}

Pesticides and herbicides are persistent and dangerous chemical compounds, among which organophosphates pesticides are commonly used as insecticides. They are generally the most toxic pesticides for animal species especially vertebrate animals (1). Organophosphorus (OP) compounds have been used in agriculture, industry, medicine, farming, animal keeping and household to destroy insects, worms, nematodes, fungus and weeds for 5 decades (2-5). Unfortunately, the improper use of these products, damage the environment including plants, animals, ground or soil and water, leading to resistance which is an increasing concern in this field $(6,7)$. Residual amounts of organophosphate insecticides are detectable in soil, vegetables, tissue of organisms, grains, and other foods products (7). These pesticides are absorbed by body through the skin and mucous membranes via oral cavity and inhalation (8). It affect various organs of the body including liver (9), kidneys, pancreas (10), immune system $(11,12)$, urinary $(13)$ and reproductive systems (14). Re- searches have shown that several factors such as duration and concentration of DZN affect its toxicity $(7,15)$.

Diazinon (DZN) (o,o-diethyl-o-[2-isopropyl-6-methyl-4-pyrimidinyl]phosphorothioate) is an OP pesticide which is extensively used to control households insects and vegetable crops (16). DZN inhibit Acetylcholinesterase (AChE) activity in the target tissues, which is the most important action of DZN compound (3). In addition to its inhibitory effect on $\mathrm{AChE}$, oxidative stress is the other mechanism involved in DZN toxicity. This leads to the formation of Reactive Oxygen Species (ROS) and changes the enzymatic activities associated with antioxidant defense mechanisms in the body $(17,18)$.

In normal conditions, there is a fine balance between ROS and antioxidant enzymes in different tissues including the ovary and testis (19). Oxidative Stress (OS) is the result of the imbalance between ROS generation and antioxidants in the body. OS can lead to sperm DNA damage, abnormal sperm morphology and finally male infertility. OS is considered as the major etiological factor leading to 
sperm damage (20).

Until recently, ROS was considered toxic exclusively to human sperm cells. However sufficient evidence exists that suggests small amounts of ROS are necessary for spermatozoa to acquire fertilizing capabilities. Low levels of ROS have been shown to be essential for sperm acrosome reaction, motility, hyperactivation, capacitation and fertilization (21-23). ROS affect multiple physiological procedures from oocyte maturation to fertilization. Although ROS may have a regulatory role in oocyte maturation, folliculogenesis, luteolysis and ovarian steroidogenesis, it can cause tissue damage as lipid peroxidation when it is produced in large amount (24-27).

One of the by-products of lipid peroxidation is Malondialdehyde (MDA). MDA is a major oxidation product of polyunsaturated fatty acids peroxidation and elevated MDA content is a significant indicator of lipid peroxidation $(7,28)$. Thiol groups are sensitive to oxidative damage and normally decrease in response to oxidative stress (29). Glutathione (GSH) is one of the thiol groups, which has an essential role in protecting cells from damage induced by oxidative stress (30).

Antioxidants are scavengers that detoxify excessive ROS and have an important role in maintaining oxidant/antioxidant balance in the body (31). Vitamin E is known as a fat soluble antioxidant which interrupts release of lipid peroxidation in the plasma membrane and thus maintains the integrity of the membrane. Many studies had showed that vitamin $\mathrm{E}$ inhibits oxidative stress and lipid peroxidation induced by OP pesticides in experimental animals $(32,33)$ and therefore prevented the adverse effects of active oxygen radicals on spermatogenesis and sperm health (34). Furthermore, antioxidants have substantial role in the female reproductive system (22).

Considering the mentioned evidences and exposure of men and women to OP poisons including DZN, and lack of enough studies evaluating and comparing the oxidative stress induced by DZN in reproductive organs (testis and ovary) of rats, the aim of present study was to evaluate and compare the effects of DZN on MDA and GSH levels in ovary and testis of rats. We also aimed to evaluate the role of vitamin $\mathrm{E}$ in protecting rats' reproductive organs (testis and ovary) against oxidative stress induced by DZN and to find the gonad at higher risk, in order to develop proper protective measures.

\section{Materials and Methods}

Animals

In this interventional study, 60 adult Wistar rats including 30 male and 30 female rats were purchased from the Animal Center, School of Medicine, Mashhad University of Medical Sciences. The rats were housed in a room under standard laboratory conditions ( $12 \mathrm{~h}$ light, $12 \mathrm{~h}$ dark at $22^{\circ} \mathrm{C}$ ) with free access to water and food. Each of the male and female groups included 30 rats and were divided into 5 groups: control (without any intervention), sham group (received only pure olive oil daily), treatment group 1 (received DZN+ olive oil daily, $60 \mathrm{mg} / \mathrm{kg}$ ), treatment group 2 (received DZN, $60 \mathrm{mg} / \mathrm{kg}$ + vitamin E, $200 \mathrm{mg} / \mathrm{kg}$ daily) and treatment group 3 (received vitamin E daily, $200 \mathrm{mg} /$ $\mathrm{kg}$ ). In this study, olive oil was used as solvent (14,35-39). DZN and solvent were administrated by intraperitoneal injection and vitamin $\mathrm{E}$ was given by gavage. According to the sexual cycle, male animals were sacrificed after 6 weeks and female rats after 2 weeks. MDA as a marker of lipid peroxidation and GSH content were determined in ovary and testis tissues.

\section{Chemicals}

For this study, technical DZN was used. DZN was dissolved in olive oil. Malondialdehyde tetrabutylammonium, reduced GSH, DTNB [5, 5' dithiobis-(2-nitrobenzoic acid)] and vitamin $\mathrm{E}$ ( $\alpha$-tocopherol acetate) were purchased from Sigma.

\section{Lipid peroxidation test}

The amount of lipid peroxidation was assessed through the measurement of MDA levels in ovary and testis tissues. MDA reacts with Thiobarbituric Acid (TBA) and produces a pink colored complex which has the maximum absorbance at $532 \mathrm{~nm}$. To start working, $3 \mathrm{ml}$ phosphoric acid $(1 \%)$ and $1 \mathrm{ml}$ TBA $(0.6 \%)$ were added to homogenate $10 \%$ tissue in $\mathrm{KCl}$, and then the compound was heated for $45 \mathrm{~min}$ in a boiling water bath. After cooling the compound, $4 \mathrm{ml}$ of n-butanol was added to it and vortex-mixed was used for $1 \mathrm{~min}$ followed by centrifugation at $3000 \mathrm{~g}$ for $10 \mathrm{~min}$. Then the organic layers were removed and transferred to other tubes and absorbance level was read at $532 \mathrm{~nm}$ (40). A calibration curve was designed using Malondialdehyde tetrabutylammonium. MDA levels were expressed by $\mathrm{nmol} / \mathrm{g}$ tissue.

\section{Reduced GSH test}

GSH was evaluated in ovary and testis by the method of Moron et al (41). The basis of the work was the formation of yellow color after adding DTNB [5,5' dithiobis-(2-nitrobenzoic acid)] to compounds containing sulfhydryl groups. For this purpose, $300 \mu \mathrm{l}$ of homogenates tissue were blended with $300 \mu \mathrm{l}$ of $10 \%$ Tricolor Acetic Acid (TCA) and vortexed. After centrifugation at $2500 \mathrm{~g}$ for $10 \mathrm{~min}$, the upper layers were removed and blended with reaction mixtures containing $2 \mathrm{ml}$ phosphate buffer (pH:8) and $500 \mu \mathrm{L}$ DTNB. After $10 \mathrm{~min}$, the absorbance was evaluated at $412 \mathrm{~nm}$ using a spectrophotometer (Jenway $6105 \mathrm{uv} / \mathrm{vis}, \mathrm{UK})$. At the end, the amount of GSH was determined based on a standard curve drawn with commercially available GSH (Sigma). The GSH Levels were expressed by $\mathrm{nmol} / \mathrm{g}$ tissue.

\section{Statistical analysis}

Results are expressed as mean \pm SD. Statistical analysis was performed with ANOVA followed by Tukey-Kramer test 
to compare the differences between groups' means for each gender separately. Independent t-test was used to compare the differences for each index (GSH and MDA) between two genders in different treatments groups. In all analyzes Tukey test was used to compare means. Differences were considered statistically significant when $\mathrm{P}$ was less than 0.05 .

\section{Results}

Effects of DZN and vitamin E on GSH and MDA in male rats

The means of GSH and MDA levels in different groups of adult male rats are demonstrated in Table 1. Comparison of means of GSH content in different groups had shown no significant differences between control, sham and treatment group 3, but GSH content in these groups were significantly more than treatment groups 1 and 2 . The highest GSH content was measured in control group and the lowest content was in treatment group 1.

Comparison of means of MDA level in different treatment groups had shown no significant differences between control, sham and treatment group 3, but MDA level in these groups were significantly lower than treatment groups 1 and 2. Highest MDA level was in treatment group 1.

Effects of DZN and vitamin E on GSH and MDA in female rats

The means of glutathione and MDA levels in different groups of adult female rats are demonstrated in Table 2. Comparison of means of GSH content in different treatment groups had shown no significant differences between control, sham and treatment group 3, but GSH content in these groups were significantly more than treatment groups 1 and 2. The highest GSH content was measured in control group and the lowest content was in treatment group 1.

Comparison of means of MDA level in different treatment groups of female rats had shown no significant differences between control, sham and treatment group 3, but MDA level in these groups were significantly lower than treatment groups 1 and 2. Highest MDA level was in treatment group 1.

Effects of DZN and vitamin E on GSH in male and female rats

The means of GSH content in different groups of male and female rats are presented in Table 3. According to the obtained results, GSH content in all groups showed significant difference between the two genders $(\mathrm{P}<0.05)$. So in all the groups, GSH content in male was significantly higher than GSH content in female. Also according to the results obtained from comparison of cases with the control group, we found that GSH content decreased in male treatment group 1 by $49 \%$, and in female treatment group 1 by $65 \%$. We also found $35 \%$ decrease in GSH contents in male treatment group 2 and $51 \%$ decrease in female treatment group 2.

\section{Effects of DZN and vitamin E on MDA in male and female} rats

The means of MDA level in different groups of male and female rats are presented in Table 4. According to the obtained results, MDA level in all groups showed significant difference between the two genders $(\mathrm{P}<0.05)$. So in all the groups, MDA level in male was significantly higher than MDA level in female.

Table 1. Mean of GSH and MDA among various groups in male rats

\begin{tabular}{lll}
\hline Treatments & Glutathione & Malondialdehyde \\
\hline Control & $* 8951.285 \pm 28 / 21^{\mathrm{c}}$ & $112.64 \pm 3 / 6^{\mathrm{b}}$ \\
Sham (Olive oil $60 \mathrm{mg} / \mathrm{kg})$ & $8389.241 \pm 17 / 07^{\mathrm{c}}$ & $114.90 \pm 2 / 8^{\mathrm{b}}$ \\
T1 (DZN $60 \mathrm{mg} / \mathrm{kg}+$ Olive oil) & $4543.679 \pm 15 / 97^{\mathrm{a}}$ & $173.82 \pm 4.6^{\mathrm{d}}$ \\
T2 (DZN $60 \mathrm{mg} / \mathrm{kg}+$ Vit E $200 \mathrm{mg} / \mathrm{kg})$ & $5756.510 \pm 17 / 33^{\mathrm{b}}$ & $140.78 \pm 1 / 7^{\mathrm{c}}$ \\
T3( Vit E $200 \mathrm{mg} / \mathrm{kg})$ & $8906.913 \pm 22 / 18^{\mathrm{c}}$ & $112.07 \pm 3 / 5^{\mathrm{b}}$ \\
\hline
\end{tabular}

${ }^{*}$ Values with small different letters in columns are significantly different and similar letters are not significantly different $(P<0.05)$ in various groups. Values expressed are mean $\pm S D$ of triplicate measurement.

Table 2. Mean of GSH and MDA among various groups in female rats

\begin{tabular}{lll}
\hline Treatments & Glutathione & Malondialdehyde \\
\hline Control & $* 4908.515 \pm 35 / 55^{c}$ & $55.23 \pm 3^{\mathrm{a}}$ \\
Sham (Olive oil $60 \mathrm{mg} / \mathrm{kg}$ ) & $4663.089 \pm 17 / 07^{\mathrm{c}}$ & $45.49 \pm 3^{\mathrm{a}}$ \\
T1 (DZN $60 \mathrm{mg} / \mathrm{kg}+$ Olive oil) & $1733.461 \pm 15 / 97^{\mathrm{a}}$ & $95.41 \pm 1.8^{\mathrm{d}}$ \\
T2 (DZN $60 \mathrm{mg} / \mathrm{kg}+$ Vit E $200 \mathrm{mg} / \mathrm{kg})$ & $2394.594 \pm 42 / 98^{\mathrm{b}}$ & $78.54 \pm 2 / 7^{\mathrm{c}}$ \\
T3( Vit E $200 \mathrm{mg} / \mathrm{kg}$ ) & $4859.429 \pm 90 / 37^{\mathrm{c}}$ & $56.6 \pm 1 / 7^{\mathrm{a}}$ \\
\hline
\end{tabular}

*Values with small different letters in columns are significantly different and similar letters are not significantly different $(P<0.05)$ in various groups. Values expressed are mean $\pm S D$ of triplicate measurement. 
Sargazi et al.

Table 3. Mean of GSH among various groups in female and male rats

\begin{tabular}{lcccc}
\hline Treatments & Male (testicle) & $\begin{array}{c}\text { \% Decreasing in male } \\
\text { vs. control }\end{array}$ & Female (ovary) & $\begin{array}{c}\text { \% Decreasing in female } \\
\text { vs. control }\end{array}$ \\
\hline Control & ${ }^{*} 8951.285 \pm 28 / 21^{\mathrm{b}}$ & - & $4908.515 \pm 35 / 55^{\mathrm{a}}$ & - \\
Sham (Olive oil 60 mg/kg) & $8389.241 \pm 17 / 07^{\mathrm{b}}$ & 6 & $4663.089 \pm 17 / 07^{\mathrm{a}}$ & 5 \\
T1 (DZN 60 mg/kg + Olive oil) & $4543.679 \pm 15 / 97^{\mathrm{b}}$ & 49 & $1733.461 \pm 15 / 97^{\mathrm{a}}$ & 65 \\
T2 (DZN 60 mg/kg + Vit E 200 mg/kg) & $5756.510 \pm 17 / 33^{\mathrm{b}}$ & 35 & $2394.594 \pm 42 / 98^{\mathrm{a}}$ & 51 \\
T3(Vit E 200 mg/kg) & $8906.913 \pm 22 / 18^{\mathrm{b}}$ & 0.5 & $4859.429 \pm 90 / 37^{\mathrm{a}}$ & 1 \\
\hline
\end{tabular}

${ }^{*}$ Values with small different letters in rows are significantly different and similar letters are not significantly different $(P<0.05)$ in various groups. Values expressed are mean $\pm S D$ of triplicate measurement.

Table 4. Mean of MDA among various groups in female and male rats

\begin{tabular}{lllll}
\hline Treatments & Male (testicle) & $\begin{array}{l}\text { \% Increasing in male } \\
\text { vs. control }\end{array}$ & Female (ovary) & $\begin{array}{l}\text { \% Increasing in } \\
\text { female vs. control }\end{array}$ \\
\hline Control & $* 112.64 \pm 3 / 6^{\mathrm{b}}$ & & $55.23 \pm 3^{\mathrm{a}}$ & \\
Sham (Olive oil $60 \mathrm{mg} / \mathrm{kg}$ ) & $114.90 \pm 2 / 8^{\mathrm{b}}$ & 2 & $53.49 \pm 3^{\mathrm{a}}$ & -3 \\
T1 (DZN $60 \mathrm{mg} / \mathrm{kg}+$ Olive oil ) & $173.82 \pm 4.6^{\mathrm{b}}$ & 54 & $95.41 \pm 1.8^{\mathrm{a}}$ & 72 \\
T2 (DZN $60 \mathrm{mg} / \mathrm{kg}+$ Vit E $200 \mathrm{mg} / \mathrm{kg})$ & $140.78 \pm 1 / 7^{\mathrm{b}}$ & 24 & $78.54 \pm 2 / 7^{\mathrm{a}}$ & 42 \\
T3( Vit E $200 \mathrm{mg} / \mathrm{kg}$ ) & $112.07 \pm 3 / 5^{\mathrm{b}}$ & -0.5 & $56.6 \pm 1 / 7^{\mathrm{a}}$ & 2 \\
\hline
\end{tabular}

*Values with small different letters in rows are significantly different and similar letters are not significantly different $(P<0.05)$ in various groups. Values expressed are mean $\pm S D$ of triplicate measurement.

The obtained results also showed that MDA level increased in both male and female treatment group 1 by 54 and $72 \%$, respectively, compared with control group. We also found $24 \%$ increase in MDA levels in male treatment group 2 and $42 \%$ increase in female treatment group 2.

\section{Discussion}

DZN is used in pest control of fruits and plants. It is also used as ectoparasiticide for cattle in veterinary applications (42). DZN is absorbed from the gastrointestinal tract and rapidly metabolized (9). OP insecticides lead to biochemical and histopathological changes in several organs such as liver, kidney, immune system, pancreas, cardiac and vascular wall and reproductive system $(43,44)$. Ovary which has a main role in the reproductive function by synthesizing hormones and producing oocyte, is one of the target organs $(45,46)$. Also DZN by making changes in the DNA or in proteins bound can damage testis tissue and create mutations in spermatogonia which eventually lead to changes in the sperm morphology and function (47-49). Based on the above evidences, the aim of the study was to investigate and compare the DZN-induced oxidative stress in sexual organs (testis and ovary) and to assess the protective role of vitamin E. One of the mechanisms of toxicity of DZN is increasing oxidative stress by the generation of free radicals and tissue lipid peroxidation. To assess this toxic effect, MDA and GSH contents were determined in reproductive tissues (testis and ovary). The intensity of lipid peroxidation was assessed through measurement of MDA levels in testis and ovary; increased MDA levels are a significant indicator of lipid peroxidation.

Comparison of means of MDA levels in different groups for each gender have shown no significant difference between control, sham and treatments group 3, but the MDA levels were significantly lower in mentioned groups compared with treatment groups 1 and 2 .

One of the mechanisms of DZN toxicity is inducing oxidative stress and producing tissue lipid peroxidation. Since DZN was solely used in treatment group 1, we observed the highest MDA level and increasing tissue lipid peroxidation in treatment group 1.

Koc et al. confirmed that endosulfan and malathion exposure increase MDA levels in ovarian tissues of female rats which is an indicator of free radical formation and lipid peroxidation during metabolism of these insecticides (50). Jahromi et al. found that malathion which is one of the OP insecticides, also may increase MDA level in ovary (4).

In this study in both genders, due to administration of DZN, we found significant reduction in GSH content in treatment group 1. Razavi et al. reported that exposure to DZN significantly increased MDA level and decreased GSH contents in heart tissue (51). Shah et al. reported that DZN administration induces lipid peroxidation in a dose-dependent style in rats. They also demonstrated that DZN treatment decreased renal GSH, reduced the activities of antioxidant enzymes including the enzymes involved in GSH metabolism and large production of oxidants which is associated with renal damage. All of them are involved in cascade of events leading to DZN-mediated renal oxidative stress and toxicity (1). Ahmadi et al. showed that DZN increased GST enzyme activity in spleen tissue and increased consumption of GSH, which indicate the increase of body's defense against toxin, and 
its rapid excretion (52). The reduced GSH reservoir in the body and reduced antioxidant activity in many tissues following the use of OPs were observed (53).

Based on above reported results, DZN induces peroxidation of lipid and increases formation of free radicals in rats' reproductive tissues which cause oxidative stress. Therefore gonads of both genders are vulnerable to oxidative stress induced by DZN and related damages. The damages induced by oxidative stress in male include lipid peroxidation of sperm membrane; decreased sperm motility and damage to DNA, sperm nucleus and protein, which may change the structure and function of sperm and play a role in infertility $(54,55)$. Oxidative stress in female can damage female fertility in different ways by affecting ovulation, fertility, embryo development and implantation. So it is considered as a main infertility factor in female (56). Considering the importance of comparing the vulnerability rate of male and female rats' gonads to DZN-induced oxidative stress and the lack of proper studies in this field, this study was performed to evaluate and compare the effects of DZN on MDA and GSH levels and oxidative stress in reproductive organs of rats and to find the more vulnerable gonad, in order to help with the development of proper protective measures.

Many authors have studied gender-related differences in pesticide toxicity in rats. Gaines et al. (57) study showed that most of the tested pesticides were more toxic to female rats. Edson and Noakes showed that male rat was more susceptible to DZN (58). Donald B. Davies demonstrated that the female rat was more sensitive to the toxicity of dietary DZN as compared to the male (59). This study however was under taken to determine whether a difference in sensitivity to DZN-induced gonads toxicity exists between males and females.

According to the obtained results, MDA levels in all groups showed significant difference between two genders $(\mathrm{P}<0.05)$. However, MDA levels in gonad of male rats were significantly higher than gonad of female rats in all groups. Since MDA levels increased in treatment group 1 in comparison with the control group in both genders ( $54 \%$ increase in male and $72 \%$ increase in female), we conclude that DZN-exposed sexual organ of female rats (ovary) have likely more tissue lipid peroxidation compared with sexual organ of male rats (testis).

Furthermore considering the increase in MDA level in treatment group 2 compared with the control group (24\% increase in male and $42 \%$ increase in female), it indicated that despite the use of vitamin E besides DZN in these treatment groups and decrease in MDA level elevation compared with treatment groups 1, but again more tissue lipid peroxidation was observed in sexual organ of female rats compared with male rats and vitamin $\mathrm{E}$ cannot protect completely from sexual organ in both genders.

According to obtained results, GSH contents in all groups had significant difference $(\mathrm{P}<0.05)$ between the two genders. GSH content in male was significantly more than the female group in all groups. Considering the decrease in GSH content in treatment group 1 in comparison with the control group (49\% decrease in male and 65\% decrease in female), we found that the DZN-exposed sexual organ of female rats, demonstrated more decline in GSH content compared with sexual organ of male. According to the substantial role of GSH in protecting cells from damages induced by oxidative stress, we can say that female rats are more prone to the adverse effects of oxidative stress. Overall, the gonad of female rats compared with male gonads showed more increase in MDA level and further decline in GSH content. It can be concluded that gonad of female rats are likely more vulnerable to oxidative stress induced by DZN and its consequences.

Cells have several ways to reduce the effects of oxidative stress: with repairing damage or reducing oxidative damage by enzymatic and non-enzymatic antioxidants (7). Vitamin $\mathrm{E}$ as non-enzymatic antioxidant is lipid-soluble vitamin present in biological membrane $(60,61)$. Antioxidants such as vitamin E, protect sperm from ROS producing abnormal sperm, increase sperm motility, scavenge ROS, prevent DNA fragmentation and stimulate spermatozoa (20).

Studies have shown that antioxidants such as vitamin $\mathrm{E}$ have a substantial role in the female reproductive system (36).

In present study treatment group 2 received antioxidant plus DZN. We observed considerable decrease in MDA level and increase in GSH content of ovary and testis compared with treatment groups 1 (DZN treated rats). This is due to the inhibitory effects of vitamin $\mathrm{E}$ on oxidative stress and tissue lipid peroxidation.

Sutcu et al. had also showed that DZN increased lipid peroxidation in erythrocytes of rat and combinations of vitamin $\mathrm{C}$ and $\mathrm{E}$ reduced lipid peroxidation (62). Yilmaz et al. reported that oxidative stress contributes to DZN-induced brain toxicity and vitamins $\mathrm{E}$ plus $\mathrm{C}$ combination may have a protective effect on this toxicity (63). Kalender et al. showed endosulphan administration increased MDA level in rats and vitamin E protected cells and cellular structures from oxidative damage by reducing MDA level (64). Another study had reported that vitamin C and E prevent hepatotoxicity induced by methyl parathion in rats (61). Previous studies had shown that vitamin E reduced MDA level in DZN-induced heart tissue toxicity but does not prevent toxicity completely (7).

\section{Conclusion}

DZN induced lipid peroxidation and increased oxygen free radicals in the reproductive tissues in both gender. So gonads in male and female rats are vulnerable to oxidative stress and its damages including infertility. Vitamin $E$ reduced oxidative stress and lipid peroxidation induced by OP pesticides in gonads. In addition, the sexual organs of female rats compared with male rats showed more increase in MDA level and further decline in GSH content. 
Considering the effect of oxidative stress in the multiple physiological processes from oocyte maturation to fertilization, embryo development and pathophysiology of infertility, it can be concluded that female rats are more vulnerable to oxidative stress and its consequences including infertility. Therefore, it is necessary to prevent further toxin entry into the body which causes gonadal dysfunction.

\section{Ethical issues}

All the experimental protocols were approved by the Ethical Committee of Mashhad University of Medical Science.

\section{Conflict of interests}

Authors declare that there is no any conflict of interests.

\section{Acknowledgments}

The results of the present study were a part of MSc. thesis in anatomical research. This study was conducted under contract NO.911097, supported by a grant from Research Council of Mashhad University of Medical Sciences, so the authors wish to declare their gratitude to Research Council of Mashhad University of Medical Science and also to Dr. Razavi, Dr. Behrooz Mohammadzadeh and Mrs. Motajadded.

\section{References}

1. Shah MD, Iqbal M. Diazinon-induced oxidative stress and renal dysfunction in rats. Food ChemToxicol 2010;48(12):3345-53.

2. Reece R, Handson P. Observations on the accidental poisoning of birds by organophosphate insecticides and other toxic substances. Vet Rec 1982;111(20):45355.

3. Yehia MA, El-Banna SG, Okab AB. Diazinon toxicity affects histophysiological and biochemical parameters in rabbits. Exp Toxicol Pathol 2007;59(3-4):215-25.

4. Jahromi VH, Koushkaki MNER, Kargar H. The effects of malathion insecticide on ovary in female rats. National park forschung in der schweiz (Switzerland Research Park Journal) 2012; 101(5):231-5.

5. Uzun FG, Kalender S, Durak D, Demir F, Kalender Y. Malathion-induced testicular toxicity in male rats and the protective effect of vitamins $\mathrm{C}$ and $\mathrm{E}$. Food Chem Toxicol 2009; 47(8):1903-8.

6. Casas E, Bonilla E, Ducolomb Y, Betancourt M. Differential effects of herbicides atrazine and fenoxaprop-ethyl, and insecticides diazinon and malathion, on viability and maturation of porcine oocytes in vitro. Toxicol In Vitro 2010;24(1):224-30.

7. Ogutcu A, Uzunhisarcikli M, Kalender S, Durak D, Bayrakdar F, Kalender Y. The effects of organophosphate insecticide diazinon on malondialdehyde levels and myocardial cells in rat heart tissue and protective role of vitamin E. Pestic Biochem Physiol 2006;86(2):93-8.

8. Sarabia L, Maurer I, Bustos-Obregon E. Melatonin prevents damage elicited by the organophosphorous pesticide diazinon on the mouse testis. Ecotoxicol Environ Saf 2009; 72(3):938-42.

9. Kalender S, Ogutcu A, Uzunhisarcikli M, Açikgoz F, Durak D, Ulusoy Y, et al. Diazinon-induced hepatotoxicity and protective effect of vitamin E onsome biochemical indices and ultrastructural changes. Toxicology 2005;211(3):197-206.

10. Gokalp O, Buyukvanlı B, Cicek E, Ozer MK, Koyu A, Altuntas I, et al. The effects of diazinon on pancreatic damage and ameliorating role of vitamin $\mathrm{E}$ and vitamin C. Pestic Biochem Physiol 2005;81(2):123-8.

11. Handy R, Abd-El Samei H, Bayomy M, Mahran A, Abdeen A, El-Elaimy E. Chronic diazinon exposure: pathologies of spleen, thymus, blood cells, and lymph nodes are modulated by dietary protein or lipidin the mouse. Toxicology 2002;172(1):13-34.

12. Neishabouri EZ, Hassan ZM, Azizi E, Ostad SN. Evaluation of immunotoxicity induced by diazinon in C57bl/6 mice. Toxicology 2004;196(3):173-9.

13. Rodrigo L, Hernández AF, López-Caballero JJ, Gil F, Pla A. Immunohistochemical evidence for the expression and induction of paraoxonase in rat liver, kidney, lung and brain tissue. Implications for its physiological role. Chem Biol Interact 2001;137(2):123-37.

14. Joshi SC, Mathur R, Gajraj A, Sharma T. Influence of methyl parathion on reproductive parameters in male rats. Environ Toxicol Pharmacol 2003;14(3):91-8.

15. Üner N, Oruç EÖ, Sevgiler Y, Şahin N, Durmaz H, Usta D. Effects of diazinon on acetylcholinesterase activity and lipid peroxidation in the brain of Oreochromis niloticus. Environ Toxicol Pharmacol 2006;21(3):241-45.

16. Koprucu SS, Koprucu K, Ural MS, Ispir U, Pala M. Acute toxicity of organophosphorous pesticide diazinon and its effects on behavior and some hematological parameters of fingerling European catfish (Silurusglanis L.). Pestic Biochem Physiol 2006;86(2):99-105.

17. Kalender Y, Kaya S, Durak D, Uzun FG, Demir F. Protective effects of catechin and quercetin on antioxidant status, lipid peroxidation and testishistoarchitecture induced by chlorpyrifos in male rats. Environ Toxicol Pharmacol 2012;33(2):141-8.

18. Giordano G, Afsharinejad Z, Guizzetti M, Vitalone A, Kavanagh TJ, Costa LG. Organophosphorus insecticides chlorpyrifos and diazinon and oxidative stress in neuronal cells in a genetic model of glutathione deficiency. Toxicol Appl Pharmacol 2007; 219(2):181-9.

19. Agarwal A, Gupta S, Sharma RK. Role of oxidative stress in female reproduction. Reprod Biol Endocrinol 2005;3:28.

20. Agarwal A, Makker K, Sharma R. Clinical relevance of oxidative stress in male factor infertility: an update. 
Am J Reprod Immunol 2008;59(1):2-11.

21. Aitken RJ. Molecular mechanisms regulating human sperm function. Mol Hum Reprod 1997;3(3):169-73.

22. Ruder EH, Hartman TJ, Goldman MB. Impact of oxidative stress on female fertility. Curr Opin Obstet Gynecol 2009;21(3):219-22.

23. Gagnon C, Iwasaki A, Lamirande E, Kovalski N. Reactive oxygen species and human spermatozoa. Ann N Y Acad Sci 1991;637(1):436-44.

24. Behrman HR, Kodaman PH, Preston SL, Gao S. Oxidative stress and the ovary. J Soc Gynecol Investig 2001;8(1):40-2.

25. Sabatini L, Wilson C, Lower A, Al-Shawaf T, Grudzinskas JG. Superoxide dismutase activity in human follicular fluid after controlled ovarian hyperstimulation in women undergoing in vitro fertilization. Fertil Steril 1999;72(6):1027-34.

26. Ishikawa M. [Oxygen radicals-superoxide dismutase system and reproduction medicine]. Nihon Sanka Fujinka Gakkai Zasshi 1993;45(8):842-8. Japanese.

27. Possamai F, Fortunato J, Feier G, Agostinho F, Quevedo J, Wilhelm Filho D, et al. Oxidative stress after acute and sub-chronic malathion intoxication in Wistar rats. Environ Toxicol Pharmacol 2007;23(2):198-204.

28. Hariri AT, Moallem SA, Mahmoudi M, Memar B, Hosseinzadeh H. Sub-acute effects of diazinon on biochemical indices and specific biomarkers in rats: protective effects of crocin and safranal. Food Chem Toxicol 2010;48(10):2803-8.

29. Esteghamati A, Zarban A, M Dousti. Evaluation of antioxidant status and stress oxidative markers in type2 diabetes melitus. Iran J Endocrinol Metab 2002;3(4):239-45.

30. Salehi B, Vakilian K, Ranjbar A. Relationship of schizophrenia with lipid peroxidation, total serum antioxidant capacity and thiol groups in schizophrenic patient and normal population. Iran J Psychiatry Clin Psychol 2008;14(2):140-5.

31. Agarwal A, Aponte-Mellado A, Premkumar BJ, Shaman A, Gupta S. The effects of oxidative stress on female reproduction: a review. Reprod Biol Endocrinol 2012;10:49.

32. John S, Kale M, Rathore N, Bhatnagar D. Protective effect of vitamin $\mathrm{E}$ in dimethoate and malathion induced oxidative stress in rat erythrocytes. J Nutr Biochem 2001;12(9):500-4.

33. Sameni H, Haghighi S, Amjad MT. Protective effects of vitamin $\mathrm{E}$ on cyclosporine A-induced toxicity in rat testis. Koomesh 2011;12(4):Pe419-Pe427.

34. Aitken RJ, West K, Buckingham D. Leukocytic infiltration into the human ejaculate and its association with semen quality, oxidative stress and sperm function. J Androl 1994; 15:343-52.

35. Mohseni Kouchesfahani H, Parivar K, Tahamtani Y. Effect of diazinon as a pesticide on oogenesis and ovary structure of balb/c mice strain. J Sci (Kharazmi
University) 2008;8(2):143-52.

36. Oksay T, Nazıroğlu M, Ergün O, Doğan S, Özatik $\mathrm{O}$, Armağan $\mathrm{A}$, et al. $\mathrm{N}$-acetyl cysteine attenuates diazinon exposure-induced oxidative stress in rat testis. Andrologia 2013;45(3):171-7.

37. Hiremath MB, Kaliwal BB. Effect of endosulfan on ovarian compensatory hypertrophy in hemicastrated albino mice. Reprod Toxicol 2002;16(6):783-90.

38. Dhondup $\mathrm{P}$, Kaliwal BB. Inhibition of ovarian compensatory hypertrophy by the administration ofmethyl parathion in hemicastrated albino rats. Reprod Toxicol1997;11(1):77-84.

39. Sortur S, Kaliwal BB. Effect of methyl parathion formulation on estrous cycle and reproductive performance in albino rats. Indian J Exp Biol 1999;37(2):176-8.

40. Uchiyama M, Mihara, M. Determination of malonaldehyde precursor in tissues by thiobarbituric acid test. Anal Biochem 1978;86:271-8.

41. Moron MS, Depierre JW, Mannervik, B. Levels of glutathione, glutathione reductase and glutathione S-transferase activities in rat lung and liver. Biochim Biophys Acta 1979;582(1):67-78.

42. Garfitt SJ, Jones K, Mason HJ, Cocker J. Exposure to the organophosphate diazinon: data from a human volunteer study with oral and dermal doses. Toxicol Lett 2002;134(1-3):105-13.

43. Yavuz T, Delibas N, Yildirim B, Altuntas I, Candir O, Cora A, et al. Vascular wall damage in rats induced by organophosphorus insecticide methidathion. Toxicol Lett 2005;155(1):59-64.

44. Gomes J, Dawodu AH, Lloyd O, Revitt DM, Anilal SV. Hepatic injury and disturbed amino acid metabolism in mice following prolonged exposure to organophosphorus pesticides. Hum Exp Toxicol 1999;18(1):33-7.

45. Mattison DR, Thomford PJ. The mechanisms of action of reproductive toxicants. Toxicol Pathol 1989;17(2):364-76.

46. Guney M, Demirin H, Oral B, Ozguner M, Bayhan G, Altuntas I. Ovarian toxicity in rats caused by methidathion and ameliorating effect of vitamins $\mathrm{E}$ and C. Hum Exp Toxicol 2007;26(6):491-8.

47. Sarabia L, Maurer I, Bustos-Obregon E. Melatonin prevents damage elicited by the organophosphorous pesticide diazinon on mouse sperm DNA. Ecotoxicol Environ Saf 2009; 72(2):663-8.

48. Wyrobek AJ, Bruce WR. Chemical induction of sperm abnormalities in mice. Proc Natl Acad Sci USA 1975;72(11):4425-9.

49. Billig H, Chun SY, Eisenhauer K, Hsueh AJ. Gonadal cell apoptosis: hormone-regulated cell demise. Hum Reprod Update 1996;2(2):103-17.

50. Koc ND, Kayhan FE, Sesal C, Muslu MN. Dosedependent effects of endosulfan and malathion on adult Wistar Albino rat ovaries. Pak J Biol Sci 
2009;12(6):498-503.

51. Razavi BM, Hosseinzadeh H, Movassaghi AR, Imenshahidi $M$, Abnous $K$. Protective effect of crocin on diazinon induced cardiotoxicity in rats in subchronic exposure. Chem Biol Interact 2013;203(3):547-55.

52. Ahmadi S, Jafari M, Asgari A, Salehi M. Acute effect of diazinon on lipid peroxidation level and activities of antioxidant enzymes in rat spleen. J Kermanshah Univ Med Sci 2012; 16(1):1-9.

53. Altuntas I, Delibas N, Sutcu R. The effects of organophosphate insecticide methidathion on lipid peroxidation and anti-oxidant enzymes in rat erythrocytes: role of vitamins E and C. Hum Exp Toxicol 2002;21(12):681-5.

54. Saleh RA, Agarwal A. Oxidative stress and male infertility: from research bench to clinical practice. J Androl 2002;23(6):737-52.

55. Sikka SC, Rajasekaran M, Hellstrom WJ. Role of oxidative stress and antioxidants in male infertility. J Androl 1995;16(6):464-8.

56. Agarwal A, Allamaneni SS. Role of free radicals in female reproductive diseases and assisted reproduction. Reprod Biomed Online 2004;9(3):338-47.

57. Gaines TB .The acute toxicity of pesticides to rats. Toxicol Appl Pharmacol 1960;2(1):88-99.

58. Edson EF, Noakes DN. The comparative toxicity of six organophosphorus insecticides in the rat. Toxicol Appl Pharmacol 1960;2:523-39.

59. Davies DB, Holub BJ. Comparative subacute toxicity of dietary diazinon in the male and female rat. Toxicol Appl Pharmacol 1980;54(3):359-67.

60. Senthil kumar J, Banudevi S, Sharmila M, Murugesan P, Srinivasan N, Balasubramanian K, et al. Effects of Vitamin C and E on PCB (Aroclor 1254) induced oxidative stress androgen binding protein and lactate in rat Sertoli cells. Reprod Toxicol 2004;19(2):201-8.

61. Uzunhisarcikli M, Kalender Y. Protective effects of vitamins $\mathrm{C}$ and $\mathrm{E}$ against hepatotoxicity induced by methyl parathion in rats. Ecotoxicol Environ Saf 2011;74(7):2112-18.

62. Sutcu R, Altuntas I, Buyukvanli B, Akturk O, Ozturk $\mathrm{O}$, Koylu H, et al. The effects of diazinon on lipid peroxidation and antioxidant enzymes in rat erythrocytes: role of vitamins $\mathrm{E}$ and $\mathrm{C}$. Toxicol Ind Health 2007;23(1):13-7.

63. Yilmaz N, Yilmaz M, Altuntas I. Diazinon-induced brain toxicity and protection by vitamins E plus C. Toxicol Ind Health 2012;28(1):51-7.

64. Kalender S, Kalender Y, Ogutcu A, Uzunhisarcikli M, Durak D, Acikgoz F. Endosulphan-induced cardiotoxicity and free radical metabolism in rats: the protective effect of vitamin E. Toxicology 2004;202(3):22735.

Copyright $(2014$ The Author(s); This is an open-access article distributed under the terms of the Creative Commons Attribution License (http://creativecommons.org/licenses/by/4.0), which permits unrestricted use, distribution, and reproduction in any medium, provided the original work is properly cited. 